\title{
Role of Technology in Health Care Sector
}

\section{Kshipra Jain*}

Department of Economics, University of Rajasthan, Jaipur, India

The world is witnessing a tremendous shift in all its aspects barring a few and apart from territories and politics; it's the science and innovation that is shaping this new world with minimum barriers. In one of his famous books, Thomas Friedman (The world is flat) talks about the process of flattening of the world whereby physical distances are losing its meaning essentially. One of the most visible phenomenons is of an individual of particular origin with citizenship of other nation and working for company of a third nation. This is one such example and many more are easily visible in our vicinity. The underlying fact is the increasing inter-dependency of nations on each other. Though the economists classify world as developed and developing countries and it is often understood in the spirit that developing countries are in need of the developed world but it's the other way round as well. The developed and developing countries both are in need of each other. If the former excel in research and development; the latter provides with the labor and consumer market. Thus, it's the technology of one nation which is put in use by the labor of another country for the larger benefit of the global consumer.

Today the technology has made its way in every walk of life and medical sector is amongst one of those sectors which are reaping its benefits. It is because of the scientific research and innovation in health sector that mankind is successful in controlling mortality to a great extent as illustrated by a continuous increase in elderly population across the globe. The diseases which used to be epidemic are now eradicated. One may argue that newer diseases are being diagnosed in the recent years which are indeed a matter of concern. However, it's the advancement in the medical field that has brought out these diseases. Further, with the help of technology the disease diagnosed at one place can be treated with the help of experts sitting many miles away.
In India, the concept of medical tourism is booming which essentially means getting the disease cured in India at a much affordable price compared to developed world. The research carried out in one part of the world has benefitted the individual in another corner of the world. There are hardly any diseases which cannot be cured if diagnosed at an initial stage. Thanks to medical informatics that is playing a vital role in shaping the health of the population.

Inspite of the tremendous progress achieved in health care sector, it is an area of never ending experiments which initially began with controlling mortality and now extends up to improvement in quality of life. Further, the changing environment has posed several new challenges to health sector in form of new infections, bacteria, viruses, course of treatment etc. According to Michigan Technological University, medical informatics is the intersection of information science, computer science and health care. This field deals with the resources, devices, and methods required to optimize the acquisition, storage, retrieval, and use of information in health and biomedicine. The technology has thus equipped medical scientists with advanced tools to carry out their research in a much more efficient way. There are numerous surgeries which are being carried out without opening the body for example laser operations [1].

This generation thus belongs to the generation of research and development and the Journal of Health and Medical informatics provides an appropriate platform for the researchers to share their knowledge or findings with rest of the work by getting it published and also being updated with the recent innovations taking place.

\section{References}

1. http://www.mtu.edu/medical-informatics/about/overview/medical-informatics/
*Corresponding author: Kshipra Jain, Assistant Professor, Department of Economics, University of Rajasthan Jaipur, India, Tel: +91-9414931914; E-mail: kshipraaa@googlemail.com

Received March 25, 2017; Accepted March 27, 2017; Published March 30, 2017

Citation: Jain K (2017) Role of Technology in Health Care Sector. J Health Med Informat 8: e143. doi: 10.4172/2157-7420.1000e143

Copyright: (c) 2017 Jain K. This is an open-access article distributed under the terms of the Creative Commons Attribution License, which permits unrestricted use, distribution, and reproduction in any medium, provided the original author and source are credited. 